\title{
AOR
}

Selected Papers of \#AolR2021:

The 22nd Annual Conference of the

Association of Internet Researchers

Virtual Event / 13-16 Oct 2021

\section{ON THE VERGE OF COLLAPSE. FRUSTRATION EXPERIENCES WITH NETWORKED MEDIA AND THE ROLE OF SOCIAL SUPPORT}

Corinna Peil

University of Salzburg

\section{Introduction / Overview}

This proposal investigates experiences of frustration with networked media from a users' perspective. It explores how these experiences are resolved and what role helping friends and family members play in this process. Experiences of frustrations refer to concrete problems in the use of networked media. The examination of their causes and elimination helps to better understand the socio-technical logics of commercial media technologies as well as their impact on everyday life. This study seeks to offer insights into societal power relations with regard to succeeding in and shaping the ongoing digital transformation process. It thus contributes to the wider field of digital inequalities research

\section{Problem Context and Research Question}

The importance of informal support systems for the appropriation of new media technologies and acquisition of digital literacies has long been recognized and researched in numerous studies (e.g., DiMaggio and Hargittai 2001). In her study on domestic Internet use, Maria Bakardjieva (2005) coined the term "warm expert". The warm expert - who can be male or female - is familiar with the Internet or has comparatively more knowledge of it, draws attention to its possible uses, and is accessible when it comes to assistance in setting up the connection or questions about how it works. The concept of the warm expert has been taken up and further developed in several studies. Elsewhere, scholars refer to 'local experts' or 'gurus', or highlight the ongoing importance of warm experts beyond the initial phase of using a new media technology (Olsson and Viscovi 2019). Closely related is the idea of the "digital housekeeper" (Kennedy et al. 2015) who set up the network at home, maintain media devices and decide on new technological acquisitions. Digital housekeeping can be an important part of male identity; a form of housework that is done voluntarily and playfully, but also reinforces domestic power relations. With the further penetration of 
smart home technologies and the Internet of things, it can be assumed that the potential field of activity of warm experts will expand even further.

However, these insights are countered by the idea that technical expertise for the use of networked media technologies has become obsolete. In recent years, there has been a strong move towards more user-friendliness. Digital media are often characterized as intuitive and easy to use. Attributes such as plug-and-play suggest that devices are simply plugged in after purchase and then function smoothly until the end of their time. And indeed, today, much less technical expertise is needed by users compared to the early days of the commercial internet when still a high level of technical commitment was required to go online. However, despite ostensible user-friendliness, the use of networked media such as computers, tablets and smartphones has not become fully self-explanatory or frictionless. Especially, when a device becomes part of a larger media ensemble in a converged media environment, users often struggle with technologies due to the lack of interoperability, maintenance requirements, failed synchronisations, software errors, or unintentional disconnection.

Taking these considerations as a starting point, I wanted to learn more about the problems people face when using media and how they deal with them: What are the challenges? Which technologies, functions and applications are causing frustration? What solutions are being sought? And what role do warm experts play in these settings?

\section{Theoretical Background}

Theoretically, my reflections are guided by different approaches: The "media deconvergence" perspective (Peil and Sparviero 2017) highlights the disorder and messiness of converging media environments and the challenges imposed to the users by the wide-ranging process of digitization. The "domestication approach" (e.g., Silverstone et al. 1992) focuses on appropriation practices and everyday processes associated with media technologies. Of interest is the entire usage biography of a technology: starting with its purchase and ending with its integration into domestic routines and interactions. This process is understood as unfinished and in principle endless. It is characterized by discontinuities, i.e., it includes phases of re-domestication and de-domestication. Frustration experiences with media have the potential to initiate re-domestication or de-domestication processes, for example when new routines develop on the basis of technical solutions, or repeated problems with media lead to alternative practices. Inspiration also comes from "broken world thinking" (Jackson 2014), which takes disruptions and failures as a starting point for analyzing sociotechnical change. The analytical lens here is on the instability of digital technologies and infrastructures, which are continuously dependent on practices of restoration, improvisation, and reinvention - that is, on acts of repair and workarounds that can result in new possibilities of media use after a breakdown. Through the possibility of rearranging media through repair work, adapting them to specific needs, and directing modes of use, these activities are inevitably linked to questions of power.

\section{Empirical Study and Findings}


Based on an ongoing qualitative study consisting of guided interviews with individuals and 'their' warm experts about challenges and troubleshooting practices in networked media usage, as well as visualizations of support networks and their written reflection and explanation, it will be shown that a.) the use of networked technologies can be considered always on the verge of collapse, as their functioning and beneficial exploitation require significant work and depend on the constant accomplishment of tasks and doings; b.) "cold expert" relationships are gaining in importance. Following Bakardjieva, this is how I refer to the unknown people on the Internet who are consulted anonymously via online forums when questions or problems arise and who offer possible solutions to specific concerns - either in direct interaction or as a fix already published on the Internet. c.) the role of warm experts has significantly altered from predominantly male tinkerers and technical enthusiasts as prevalent in the beginning of the computer era to more heterogeneous forms of expertise and changing constellations of support and neediness. In view of constant innovations and shorter production cycles, it has also become more difficult for individuals to know more or be more knowledgeable than others. At the same time, many problems with media are highly individual. As a social process with dynamic interactions, the transfer of knowledge and practical skills is linked to new power relations and asymmetries, but also holds opportunities for creative and resistant behaviours.

\section{References}

Bakardjieva, M. (2005). Internet society: The Internet in everyday life. SAGE.

Jackson, S. J. (2014). Rethinking repair. In K. A. Foot, P. J. Boczkowski, \& T. Gillespie (Eds.), Inside technology. Media technologies: Essays on communication, materiality, and society (pp. 221-239). The MIT Press.

Kennedy, J., Nansen, B., Arnold, M., Wilken, R., \& Gibbs, M. (2015). Digital housekeepers and domestic expertise in the networked home. Convergence: The International Journal of Research into New Media Technologies, 21(4), 408-422. https://doi.org/10.1177/1354856515579848

Olsson, T., \& Viscovi, D. (2018). Warm experts for elderly users: Who are they and what do they do? Human Technology, 324-342.

https://doi.org/10.17011/ht/urn.201811224836

Peil, C., \& Sparviero, S. (2017). Media convergence meets deconvergence. In S. Sparviero, C. Peil, \& G. Balbi (Eds.), Global transformations in media and communication research. Media convergence and deconvergence. Palgrave Macmillan.

Silverstone, R., \& Hirsch, E. (Eds.). (1992). Consuming technologies: Media and information in domestic spaces. Routledge. 